\title{
Wet-Etch Figuring: Optical Surfacing by Controlled Application of Etchant Solution Using the Marangoni Effect
}

M. C. Rushford, J. A. Britten, C. R. Hoaglan, I. M. Thomas, L. J. Summers, and S. N. Dixit

This article was submitted to

Society of Photo-Optical Instrumentation Engineers $46^{\text {th }}$ Annual Meeting, San Diego, California, July 29 - August 3, 2001

May 17, 2001 


\section{DISCLAIMER}

This document was prepared as an account of work sponsored by an agency of the United States Government. Neither the United States Government nor the University of California nor any of their employees, makes any warranty, express or implied, or assumes any legal liability or responsibility for the accuracy, completeness, or usefulness of any information, apparatus, product, or process disclosed, or represents that its use would not infringe privately owned rights. Reference herein to any specific commercial product, process, or service by trade name, trademark, manufacturer, or otherwise, does not necessarily constitute or imply its endorsement, recommendation, or favoring by the United States Government or the University of California. The views and opinions of authors expressed herein do not necessarily state or reflect those of the United States Government or the University of California, and shall not be used for advertising or product endorsement purposes.

This is a preprint of a paper intended for publication in a journal or proceedings. Since changes may be made before publication, this preprint is made available with the understanding that it will not be cited or reproduced without the permission of the author.

This report has been reproduced directly from the best available copy.

Available electronically at http://www.doc.gov/bridge

Available for a processing fee to U.S. Department of Energy

And its contractors in paper from

U.S. Department of Energy

Office of Scientific and Technical Information

P.O. Box 62

Oak Ridge, TN 37831-0062

Telephone: (865) 576-8401

Facsimile: (865) 576-5728

E-mail: reports@adonis.osti.gov

Available for the sale to the public from

U.S. Department of Commerce

National Technical Information Service

5285 Port Royal Road

Springfield, VA 22161

Telephone: (800) 553-6847

Facsimile: (703) 605-6900

E-mail: orders@ntis.fedworld.gov

Online ordering: http:/ / www.ntis.gov/ordering.htm

\section{OR}

Lawrence Livermore National Laboratory

Technical Information Department's Digital Library

http: / / www.llnl.gov/tid/Library.html 


\title{
Wet-Etch Figuring: Optical Surfacing by Controlled Application of Etchant Solution Using the Marangoni Effect
}

\author{
M. C. Rushford, J. A. Britten, C.R. Hoaglan, I.M. Thomas, L. J. Summers, S.N. Dixit \\ Lawrence Livermore National Laboratory \\ Livermore, CA 94550
}

\begin{abstract}
Wet-etch figuring (WEF), a computer-controlled method for generating arbitrarily shaped optical surfaces using wet chemical etching, has been developed. This method uses applicator geometry and surface tension gradients (the Marangoni Effect) to define and confine the footprint of a wetted etchant zone on the surface. Capillary forces attach the flowing etchant solution to the underside of the optic being figured. No mechanical or thermal stresses or residues are applied to the optic by this process. This enables interferometric measurement of the glass thickness while surfacing, which then controls the placement and dwell time of the wetted zone. The result is a truly deterministic, closed-loop figuring process with a high degree of optical precision. This process can figure sub-millimeter thickness, large-aperture plates or sheets that are very difficult to finish by conventional methods. Automated linear and circular spot etching tools were used to demonstrate surfacing on 380 micron-thick glass sheets, to Strehl better than 0.8 , as specified by data array or Zernike polynomials.
\end{abstract}

\section{KEYWORDS}

Small tool figuring, surfacing, polishing, Marangoni, wet etching, aspheric, phase correction, phase mask, interferometry, surface tension

\section{INTRODUCTION}

Small-tool finishing or figuring of optical surfaces basically involves moving a small polishing tool in a controlled manner to shape the surface of an optic. It is a critical technology for producing optics for applications ranging from camera lenses for the consumer market, to large-aperture optics for inertial confinement fusion and space telescope systems. Examples of optics figured by these techniques include aspheric lenses, continuous-contour phase plates, wavefront correction optics, Alvarez lenses, Schmidt corrector plates and optics requiring local figure correction after processing via traditional lap polishing. Small-tool finishing is simultaneously a mature technology and one undergoing continuous development driven by the high cost and reproducibility problems of processes when applied to ever-tightening figure tolerances.

Traditional small-tool optical figuring techniques employ rotary polishing pads. Recent developments (1-4) utilize directed flow fields to impinge fine abrasive slurries to the optical surface. Magneto-rheological finishing (5-7), recently implemented on a commercial scale, extends this concept by controlling the viscosity of a specially formulated abrasive slurry by application of magnetic fields. Ion-beam milling techniques $(8,9)$ have been commercialized as well. These are alternative, fundamentally different methods for high-accuracy optical figuring.

All of the above-mentioned techniques suffer from fundamental limitations. They rely on calibrated removal rates, and are therefore iterative processes: the workpiece must be dismounted from the machine and measured, reworked and remeasured, until specifications are met. Ion beam milling techniques require large, expensive vacuum processing chambers and are not applicable to all materials. Abrasive small-tool polishing techniques cannot be used to figure very thin optics since the local mechanical stresses involved cause workpiece deformations that impact removal control and can even cause breakage.

Material removal on optical surfaces can be accomplished by etching or dissolution methods (e.g. silicate glasses are soluble in hydrofluoric acid solutions), but until now, wet etching has not been employed to figure optics. The problem has been largely how to confine the wetted zone of etchant solution to a specific stable geometry. A surface being etched is hydrophilic to the etching solution. If a bolus of etchant solution is moved along the surface of a workpiece, a thin liquid film will be left behind that will continue to etch the surface. In recent years, surface-tension gradient driven flow (the Marangoni effect) has been shown to be effective in causing this thin entrained film to flow off the surface of a workpiece 
back into the bulk liquid if said liquid is applied in the appropriate manner (10-14). This phenomenon has been commercialized in the semiconductor processing industry for critical wafer drying applications.

We have employed the Marangoni effect to confine the wetted zone of an etchant solution on the surface of an optic. The wetted zone size and shape remains fixed as it is moved around on the workpiece surface. This allows the fluid to act on the surface of the workpiece only in this wetted zone with no mechanical contact or induced mechanical stresses applied to the workpiece. This in turn allows for real-time local metrology of the processing, and enables the processing of very thin $(<<$ $1 \mathrm{~mm}$ thickness) large-aperture plates that cannot be surfaced by other means. This is an enabling technology for the precision figuring of very thin optics that can be used in lightweight, space and astronomy applications, high-power laser systems in which nonlinear effects due to bulk transmissive optics need to be minimized, display applications, pellicles, etc.

\section{PROCESS DESCRIPTION}

Liquid flows induced by surface tension gradients are generally known as Marangoni flows in honor of a 19th century Italian physicist who is credited with their elucidation (cf. 15). Thermal or concentration gradients can establish surface tension gradients. We have employed concentration gradients of absorbed low-molecular weight volatile organic compounds (VOC's, e.g. isopropanol) in a geometry in which the optic surface is etched from below (see Figure 1). The aqueous etchant flows slowly up through a small tube (or slot, in a one-dimensional tool) and flows out and down the outside of the tube or slot. Capillary forces cause the liquid to attach to the underside of an optic when it is placed in close proximity to the exit orifice. In the absence of surface tension gradients, a liquid film remains behind on the surface when it is translated with respect to the liquid applicator. VOC's introduced in the volume surrounding the fountain, either by natural evaporation from a pool, or convection in a carrier gas, absorb into the liquid. Greater concentrations of absorbed VOC build up near where the liquid meniscus attaches to the glass than lower down the meniscus where the falling film flow on the outside of the applicator refreshes the surface. This concentration gradient results in a surface tension gradient strong enough to pull the liquid film off of the surface as is moves laterally, resulting in a wetted zone of constant, stable size. The shape of this zone is fixed by the applicator geometry and to a lesser extent by the flow rate and the spacing between the orifice and the workpiece. Figure 2 shows a circular wetted zone for a two-dimensional figuring tool, and a linear wetted zone in a line-source geometry used to take the one-dimensional phase ripple out of commercially extruded thin sheet glass.
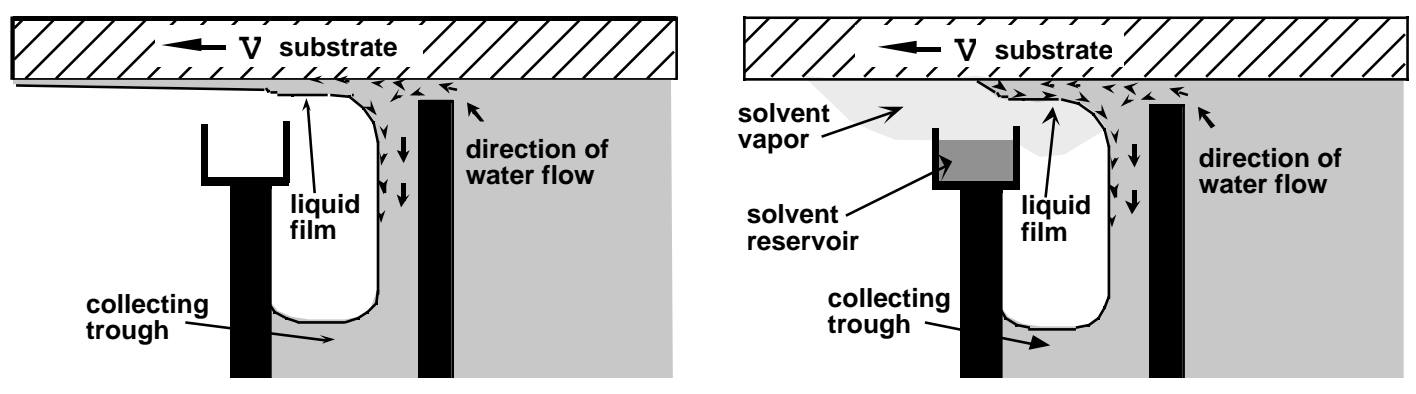

Figure 1. Schematic of Marangoni effect applied to aqueous etchant confinement. Left: water flowing over a dam with a glass sheet just over the dam being wetted as the glass is translated from right to left. Water in this case will adhere to the hydrophilic glass surface and remain behind as a film. Right: In the presence of VOC vapors (e.g. isopropanol) that absorb into the water film and reduce its surface tension, a surface tension gradient is established, lowest in the relatively quiescent thin film flow on the glass and highest in the continuously refreshed falling film zone. This gradient is strong enough to pull the liquid film off of the surface and maintain a wetted zone of constant size as the substrate is translated. 


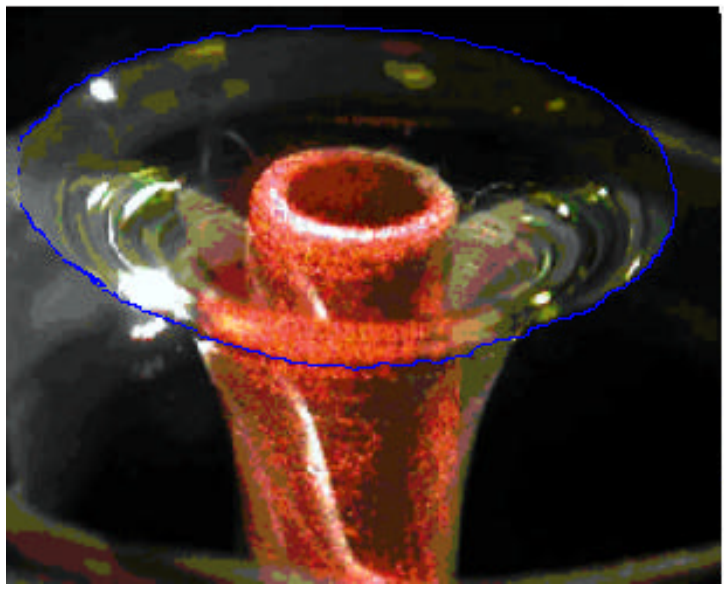

A

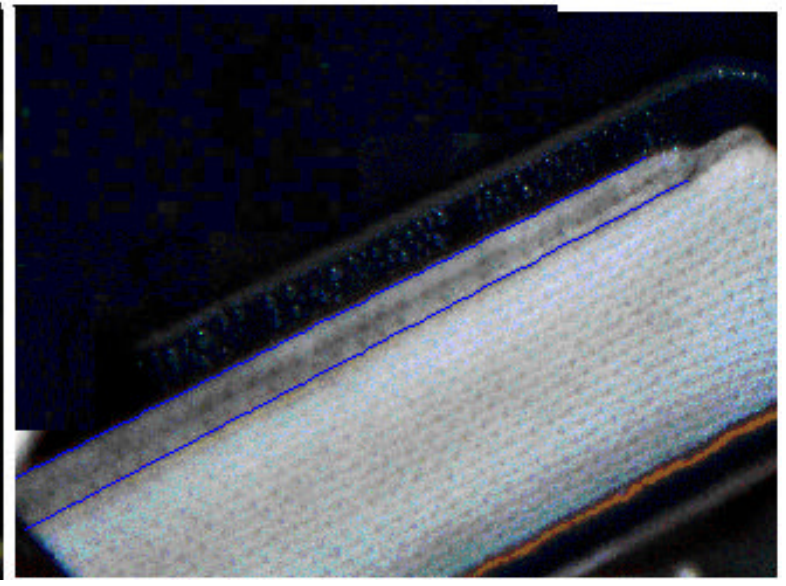

B

Figure 2. (A) Looking downwards through the thin glass being processed, left is a drop of etchant solution $\sim 10 \mathrm{~mm}$ in diameter adhering to the underside of a glass sheet. The solution is flowing up through and then down the outside of the tube. (B) A 150x10-mm rectangular wetted zone in which liquid flows up out of a slit and down the inclined plane on either side. In both cases, a blue line has been drawn on the three-phase contact line as a visual aid.

A key element to the technology is the ability to measure while figuring in a feedback control loop that makes the process truly closed-loop controllable. In situ real-time interferometry is used to measure the surface shape as shown in Figure 3.

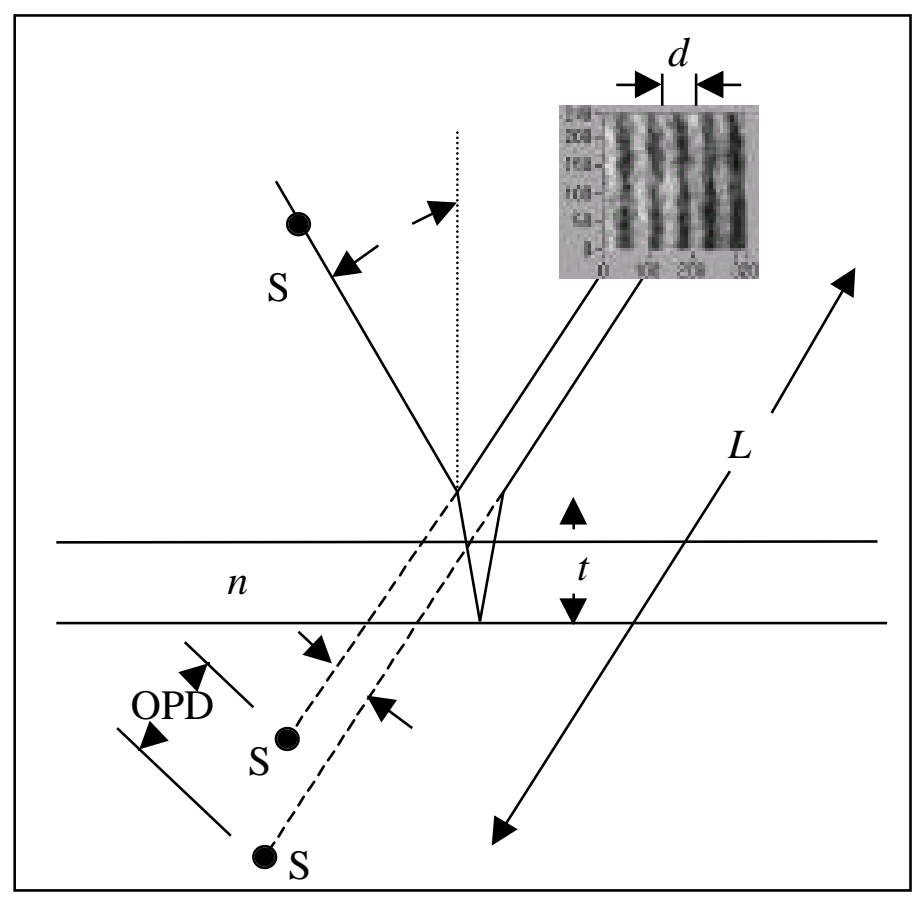

A

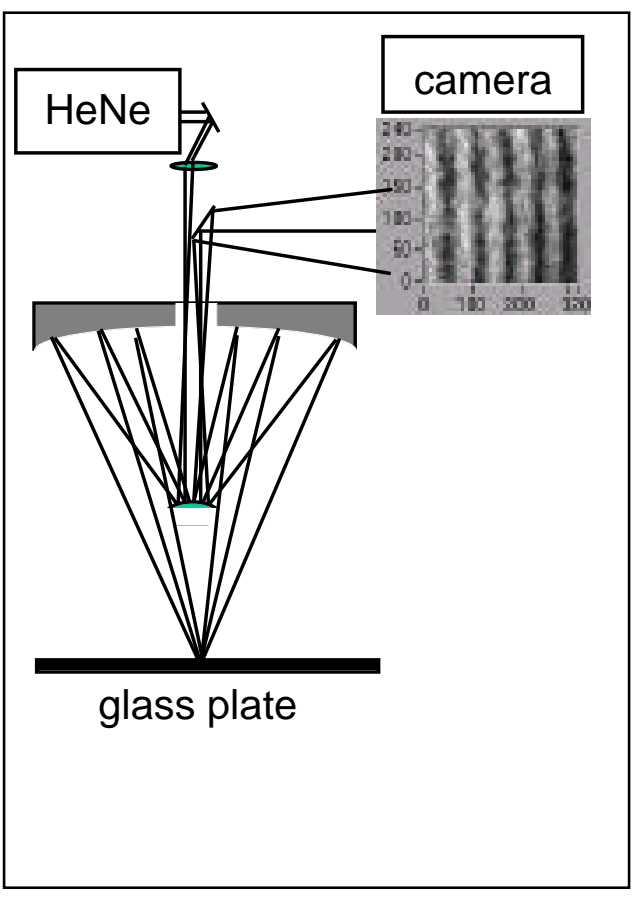

B

Figure 3. (A) Is a schematic layout showing the creation and relative displacement between two divergent light source S' and S" which give rise to uniformly spaced fringes. (B) Shows how the source $\mathrm{S}$ can be created while also projecting the fringes to a camera. 
A point source (S) of coherent light illuminates the glass sheet from above directly over the etching head and at a slight angle. Two virtual point sources $\left(\mathrm{S}^{\prime}\right)$ and $\left(\mathrm{S}^{\prime \prime}\right)$ appear in reflection from this glass plate and produce Interference fringes. At a given glass thickness $(t)$ and angle of incidence $(\alpha)$ the apparent source shear separation $(\mathrm{X})$ is given by:

$$
\mathrm{X}=2 t \sin (\alpha)
$$

The two sources are further separated in Optical Path Difference $(O P D)$ :

$$
O P D=2 n t \cos \alpha
$$

where $(n)$ is the glass index of refraction. These two-beam interference fringes translate in phase as the glass thickness $(t)$ changes. The fringe phase and thus the relative change of the OPD is measured and scaled to control the tool dwell time. The fringe period $d$ is given by:

$$
d=L \lambda / \mathrm{X}
$$

where $(L)$ is the distance from the source to the fringe projection plane and $(\lambda)$ is the laser wavelength. In practice, a 633-nm $\mathrm{HeNe}$ laser source (S) is focused within a few $\mathrm{mm}$ of the glass surface using the geometry shown in Figure 3B. The interferometer fringe stability is very robust to machine vibrations due to its common-path design.

The glass relative thickness is measured from relative phase of the fringes on the camera. While in closed loop control the glass bottom side reflectivity is reduced because this interface being contacted with etchant, reducing fringe visibility to 0.1 . The two dimensional digitized raw fringe intensities are seen in Figure 4 (A). A single one-dimensional array is made by summing column pixels along the fringe length to increase the fringe signal-to-noise. This one-dimensional sinusoidal array is FFT band-pass filtered to further improve the signal-to-noise ratio and generate the sinusoidal intensity pattern. This data is binned into 4 data zones $R_{0}-R_{3}$ spanning a fringe period from PK1 to PK2, as shown in Figure 4B. The scalar values $I_{0^{-}}$ $I_{3}$ are sums of these data regions. These values are used to calculate the fringe phase $\Phi$ according to the algorithm developed by Schwider et al. (16), relative to these fixed regions:

$$
\tan (\Phi+\pi / 4)=\frac{2\left(I_{0}-I_{2}\right)}{I_{0}-\left(I_{1}+I_{2}\right)+I_{3}}
$$
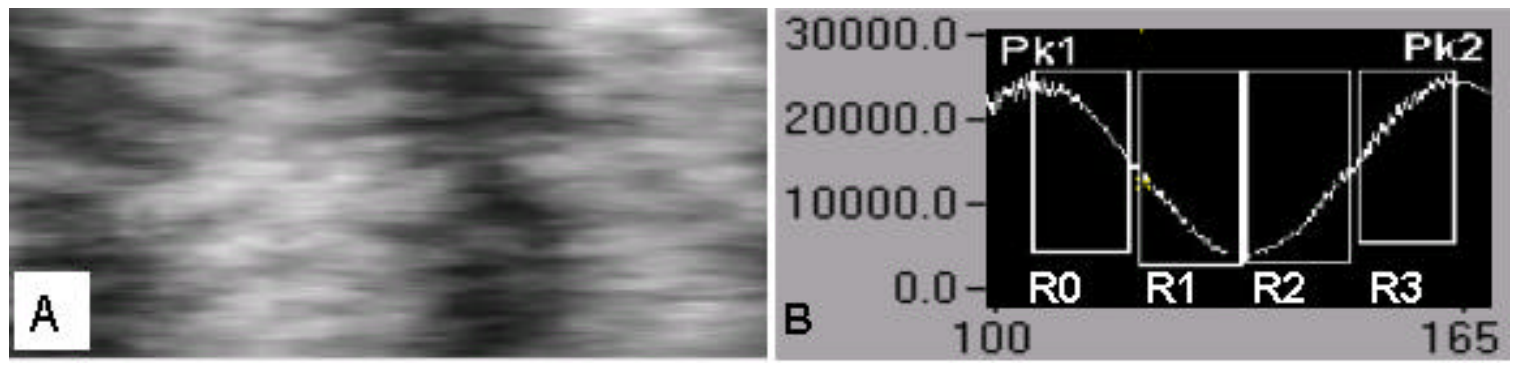

Figure 4 (A) Raw interference-fringes seen in reflection off a 380-micron thickness glass plate when wet by water on its bottom side. The fringes are exhibit speckle from the coherent source at $633 \mathrm{~nm}$ and imperfections in the optics. (B) Summed and filtered intensity profile binned into 4-zones for phase-stepping algorithm.

The area to be figured is divided into $m$ by $n$ pixels. The dwell time per pixel is scaled from real time relative thickness measurements as described above. The pixel size is chosen to be smaller than the tool size to ensure smooth figuring. The dwell time is a velocity of passage over a pixel. The dwell algorithm is to move the tool as rapidly as possible over areas that do not require surface removal. This top speed limit is set by the surface tension confinement strength of the wetted zone, and has comfortably demonstrated $1000 \mathrm{~mm} / \mathrm{min}$, The slowest speed, used where material removal rates are to be maximized, is typically 10-20 times less than the top speed. If the rate becomes too slow, etching of patterns on the scale of the tool size begins to become a problem. 


\section{DEMONSTATIONS OF THE PROCESS}

\section{$\underline{\text { One Dimensional Smoothing of Sheet Glass }}$}

Many types of commercial extruded thin glass sheet products exhibit a reasonable transmitted wavefront in the draw direction, but suffer from several waves of optical distortion perpendicular to the draw direction. These multi-component glass sheets are available in dimensions greater than one meter and thickness ranging from 100 microns to a few millimeters. Until this time, there has been no method to flatten such large thin sheets to optical tolerances at a reasonable cost.

As a proof-of-principle experiment, we constructed a 1-D etcher wherein a stepper-motor stage moved a glass sheet over a slotted orifice $150 \mathrm{~mm}$ long, creating a wetted zone of this length and about 2-10 mm wide. Interferometric measurements were taken along one line, and used to control the wetted zone dwell time. A 150 -mm wide by 200-mm long section of Corning 0211 glass, 380 microns thick, was processed using a buffered HF solution over a continuous 96-hour period. The transmitted wavefront of the result is shown in Figure 5. Over 12 microns PV were removed. There is about 1 wave residual 2-dimensional error remaining on the flattened section. A second demonstration using a higher etchant concentration and 10-30-mm wide by 400-mm long wetness footprint was used to flattened 6.5 microns of excursion on a 400x400-mm-square section of $0.75-\mathrm{mm}$ thick Corning 1737 glass in 24 hours. Profiles of the plate thickness measured at the control line at the start and end of the process are shown in Figure 6.

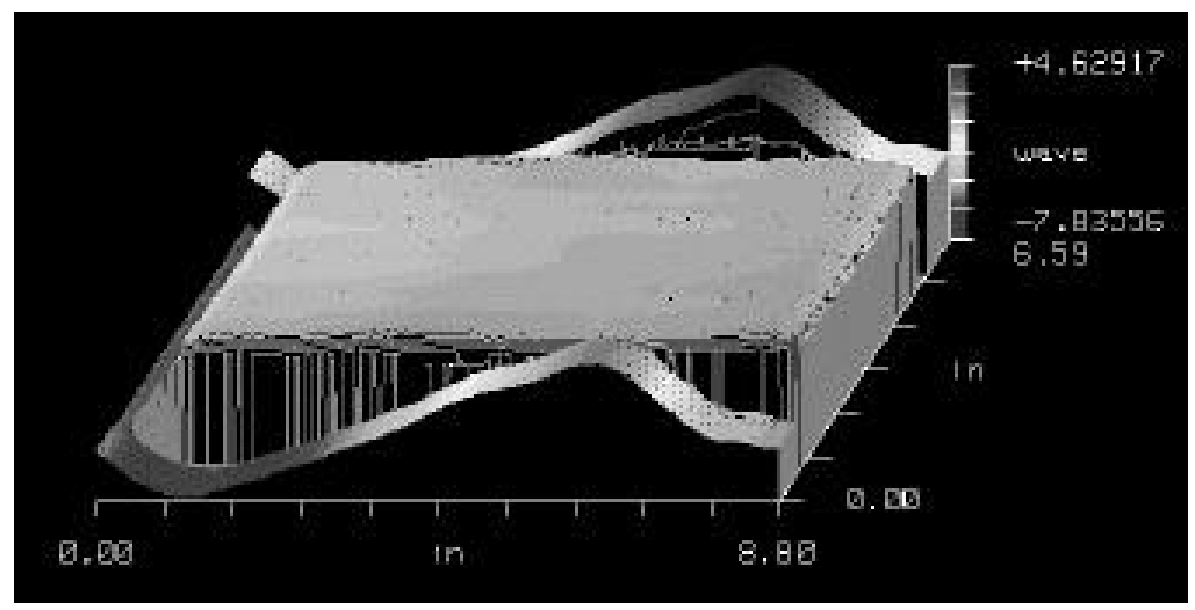

Figure 5. Transmitted wavefront of 150 x 200-mm section of 380 micron-thick glass plate flattened using linear etching tool. Apparent discontinuities in profiles along edges caused by fringe dropouts at high-gradient zone along edges. Approximately 9 waves of distortion in transmitted wavefront taken out, leaving $\sim 1 / 2$ wave of residual 2-dimensional error across the part.

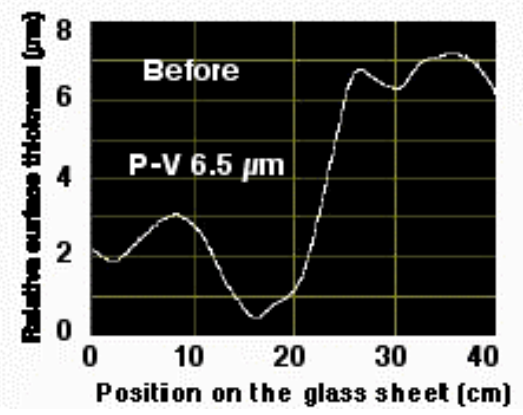

A

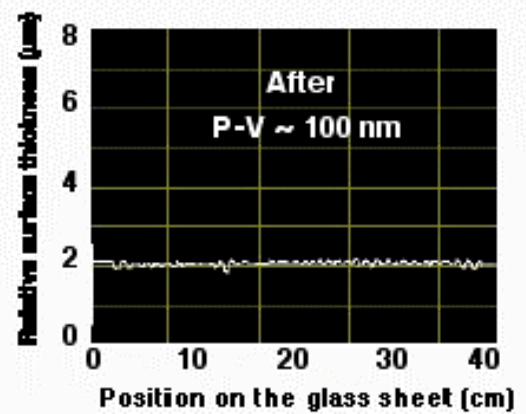

B

Figure 6. Sheet thickness lineout used for process control for figuring Corning 1737 400x400x0.7 mm thick sheet. (A) At start and (B) and after $24 \mathrm{hrs}$ figuring with one-dimensional WEF tool. 


\section{Fabrication of a Beam-Shaping Phase plate}

An ultra-short pulse laser-cutting application at LLNL (17) can improve upon hole-drilling performance by use of a top-hat beam as opposed to a gaussian beam at focus. We designed a phase plate to transform a far field gaussian beam at $1030 \mathrm{~nm}$ into a flatter intensity profile before and after focus. It is essentially a lens of weak power but has spherical aberration. We fabricated this design using a circular 2-D WEF tool to figure this design out of 380 micron-thick, Corning 0211 glass, at $2.3-\mathrm{cm}$ aperture. The substrate was mounted on a $\mathrm{x}-\mathrm{y}$ stepper motor stage and glass thickness was mapped in-place interferometrically. This map and subsequent updates were used to control the dwell time of a circular WEF spot that varied from $\sim 5-\mathrm{mm}$ diameter at the start and shrinking to $\sim 1 \mathrm{~mm}$ in diameter near the end of the working time. The final residual surfacing error was used to calculate the Strehl ratio. This criterion was used to determine when the part was finished. Several phase-plates of this design have been manufactured. Figure 7 shows the transmitted wavefront of one fabricated phaseplate that exhibited a residual surface error Strehl ratio of better than 0.85 . The optic was finished in about 18 hours of continuous, automatic operation. This optic is now being used in routine laser-cutting operations.
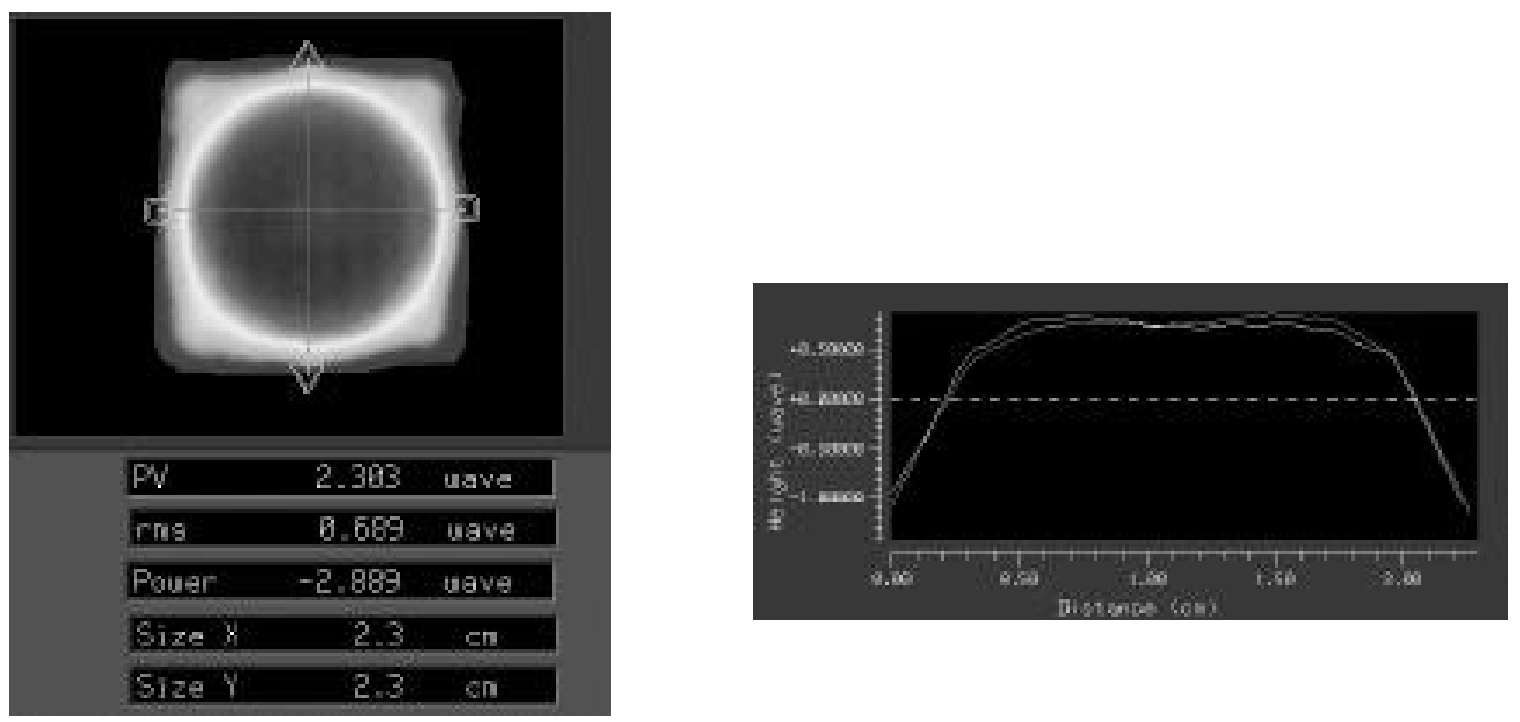

Figure 7: Transmitted wavefront of phase-plate figured with automated 2-dimensional WEF tool - to convert $1030 \mathrm{~mm}$ gaussian profile at focus to top-hat profile. Surface was contoured in 380-micron thick Corning 0211 glass with 23-mm aperture. Its residual error Strehl was 0.85 .

\section{Static Wave front Corrector for a High-Power Laser System.}

Most high power laser systems suffer from wavefront aberrations that are both static and dynamic. Adaptive optical elements such as deformable mirrors are typically employed to compensate for most aberrations. However, it is highly desirable to use a static wavefront 'pre-corrector' in the optical chain to correct for static aberrations and reduce the dynamic range required for the active wavefront control device. Researchers at the AWE facility in the United Kingdom have designed a static wavefront corrector for their purposes that calls for a complex surface with 12 microns PV departure over a $80 \mathrm{~mm}$ circular aperture (18). Attempts at fabricating this corrector by a gray-scale photo-resist profile exposure followed by reactive ion etching to transfer the continuous profile into fused silica were of limited success, due to the lack of active process control to converge on the desired profile. Multilevel binary approximations to the continuous profile are less desirable due to intensity modulations that are known to occur at sharp edges that are capable of damaging downstream optics.

We have fabricated a corrective optic to specifications given by Zernike polynomials by the WEF technique, using the circular 2-D tool described above. This optic profile was a considerable challenge to fabricate and led to many process and 
control improvements. Processing of data at the edges of the part where steep gradients are etched over time was a significant problem. We employed a "corona guard band" strategy to overcome this. This zone spanned the distance from the circularly defined optic to a rectangular region $1 \mathrm{~cm}$ away from the optic. Whatever the dwell time was supposed to be at the edge of the optic was radially carried outward to the outer guard band frame edge. The final transmitted wavefront profile at $80-\mathrm{mm}$ aperture shown in Figure 8. The part was completed when the surfacing was within $100 \mathrm{~nm}$ of target. The residual error of the part is equivalent to a Strehl of 0.26. Since the process is controlled to the final figure, this optic was made in one step.
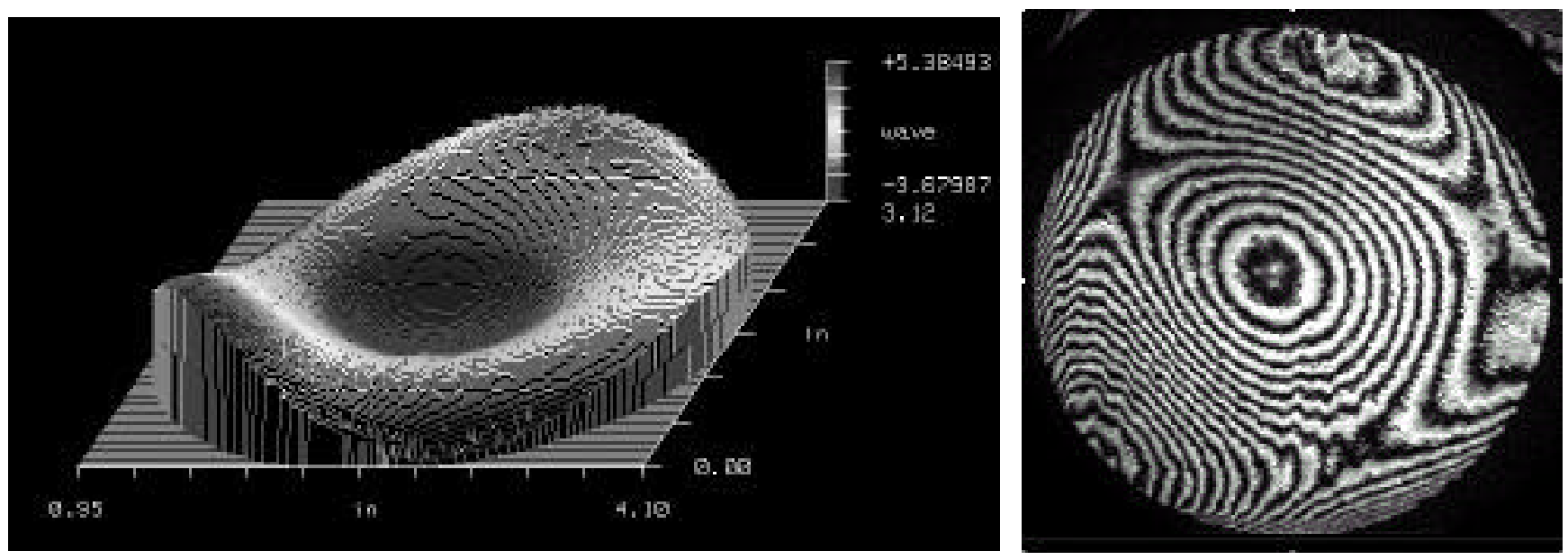

Figure 8. Interferogram of static wavefront corrector for AWE's Helen laser, fabricated with automated 2-dimensional WEF tool. $80 \mathrm{~mm}$ aperture. PV of this figure is 12 microns. It achieved a residual Strehl of 0.26.

\section{DISCUSSION}

Conventional polishing processes require more mechanical force as the tool size increases. The complexity and power requirements in ion-beam figuring increase substantially as the ion source size is increased. In contrast, it is quite easy to tailor the tool size in wet-etch figuring. The wetted zone can be made arbitrarily large and arbitrarily shaped without distorting the optical surface being figured. Furthermore, under conditions in which the surface removal rate is kinetically controlled, the etch rate is independent of local flow conditions and is constant everywhere in the wetted zone. Since the tool area is flexible, it is possible to rapidly work large area of low spatial frequency and later shrink the wetted zone size to finish off the higher frequency components of a surface shape. We have made applicators varying in wetted-zone size from $1 \mathrm{~mm}$ to $15 \mathrm{~mm}$ in diameter with a circular shape and $400 \mathrm{~mm}$ long fixed by 1-30 mm variable width for doing 1D profiles. The size of the wetted zone is easily customized to the particulars of a surface contour.

To date we have done the majority of our work on Corning 0211 (zinc borosilicate) sheets. We have used HF concentration of $0.5 \%-10 \%$ buffered with $\mathrm{NH}_{4} \mathrm{~F}$, or in combination with a mineral acid (nitric or hydrochloric) added to solubilize the non-silicate components of this glass. We have also etched pure fused silica and Corning 1737 (an alkaline-earth aluminosilicate). The etching rate is dependent on the glass solubility, etchant composition, temperature and concentration. This process is operated under ambient temperature and for concentration conditions that ensure that the etching rate is controlled by chemical kinetics and not influenced by mass transport phenomena. Of course, the exact etch rate need not be known, since the removal rates are measured in real time. On 0211 glass we have worked etching rates from 10 to 900 $\mathrm{nm} /$ minute. The time to finish a profile is the ratio of the volume of material to remove divided by the volume removed per unit of time by the tool. We never have to stop production to inspect progress, as it is measured in real-time. Since the tool area can be increased to arbitrary size and shape it becomes possible to decrease the working time by customizing the wet foot print tool area for some routinely similar work.

If the wetted zone size is constant over the course of the etching, the surface profile gradually develops discontinuities. Pulsating the etchant flow to cycle the size of the wetted zone alleviates this effect. This imparts a more Gaussian etch rate 
profile on average and minimizes sharp gradients at the tool edges. High-frequency tool-generated surface ripples were also minimized by reducing the tool size at later times in the figuring process and by keeping the ratio of high-to-low dwell times no greater than 5:1. We have also found it advantageous to provide a wicking effect on the outside of the applicator, to reduce the effective tool size to on the order of the orifice dimension, for final high-frequency figuring work. Glass fogging was observed if we were not careful to completely flush acid vapors from the vicinity of the etch head, by supplying an adequate flow of carrier gas to serve a dual purpose as a flushing gas as well as to supply isopropanol vapors.

Since WEF is a figuring process and not a polishing process, the micro-roughness of the surface is not improved upon figuring, and in fact could be worsened, depending on the degree of subsurface damage left by prior polishing processes, and by the degree of bulk inhomogeniety of the glass. This may limit its application in some critical applications where scatter loss is of primary concern. However, this figuring method may alleviate some other problems often associated with conventional polishing. Abrasive compounds at the sub-micron scale left behind in the gel layer upon final polish have been shown to significantly degrade the laser damage threshold of optics used for high-intensity UV laser applications (19). The WEF process leaves no residues behind, and in fact can remove residues, so in principle it can improve the laser damage characteristics of optical surfaces. Since WEF imparts no subsurface damage, the glass remains mechanically strong.

\title{
FUTURE APLICATIONS
}

We are presently building an apparatus to remove the primary one-dimensional ripple from drawn glass sheets $1160 x 850-$ $\mathrm{mm}$ by $0.7 \mathrm{~mm}$ thick. This same tool will be outfitted with an adjustable wetted-zone width capability along its length, to remove the residual two-dimensional random errors left in these sheets. A 2D image-wise interferometer has been developed and its data output will be used to control the WEF width variations. The goal is to produce $800 \times 800 \times 0.7 \mathrm{~mm}$ sheets that are optically flat to less than 1/8 wave in transmission. These will be used as segments in a 5-meter diameter foldable Fresnel lens for space applications $(20,21)$. We are also investigating the manufacture of $400 \mathrm{~mm}$ square, $10 \mathrm{~mm}$ thick random continuous contour phase plates for beam homogenizing on LLNL's NIF laser system (22) as well as wavefront corrective optics. We will look into making continuously varying gray scale apodizers having embedded phase correction, in which an initially uniform gray scale is selectively tailored by etching. We are exploring the utility of this process for figuring of fused silica pellicles for deep UV lithographic imaging systems (23). It is also possible to use a shearing interferometer (24) to measure the front surface contour of opaque substrates to control WEF processing of these surfaces.

\section{CONCLUSIONS}

A process for closed-loop computer-controlled figuring of optical surfaces by Marangoni-confined wet-etch figuring has been demonstrated. Unlike other figuring techniques, no mechanical or thermal stresses are applied to the workpiece in this method. No residue is left on the optic. This allows for in-situ interferometric metrology of the workpiece during figuring, to control the placement and dwell time of the wetted zone locally on the workpiece. Thus, figuring is truly deterministic, eliminating the figure/measure iterative cycle. The lack of stress experienced by the substrate also allows for the figuring of very thin, sub-millimeter thickness optical glasses to precise optical tolerances, something that is achievable only at great expense using existing techniques. The process is simple to implement, automated, operates at ambient conditions, and requires no elaborate or expensive calibration or tooling.

Acknowledgements: The authors thank J.Toeppen and R. Shuttlesworth for helpful assistance during this project. This work was performed under the auspices of the U.S. Department of Energy by UC/LLNL under contract no. W-7405-Eng-48.

\section{REFERENCES}

\author{
1. Taylor, J.S., 'Precision Non-Contact Polishing Tool', U.S. Patent 5,591,068 \\ 2. Baker, P.C., 'Advanced Flow Polishing of Exotic Optical Materials', SPIE V. 1160, 263-270, (1989) \\ 3. Fahnle, O.W., van Brug, H., Frankena, H.J., , 'Fluid Jet Polishing of Optical Surfaces', Applied Optics, 37, 6771-6773, \\ (1998)
}


4. Fahnle, O.W., van Brug, H., 'Fluid Jet Polishing: Removal Process Analysis', Proc. SPIE, V. 3739, 68-77, (1999)

5. Jacobs, S.D., Kordonski, W., Prokhorev, I.V., Gollini, D., Grodkin, G.R., Strafford, T.D., 'Deterministic Magnetorheological Finishing', U.S. Patent 5,795,212 (1998)

6. Golini, D., Kordonski, W.I., Dumas, P., Hogan, S.J., 'Magnetorheological finishing (MRF) in Commercial Precision Optics Manufacturing', Proc SPIE, V. 3782, 80-91, (1999)

7. Jacobs, S.D., Arrasmith, S.R., Kozhinova, I.A., Gregg, L.L., Shorey, A.B., Romanofsky, H.J., Golini, D., Kordonski, W.I., Dumas, P., Hogan, S., 'MRF: Computer-Controlled Optics Manufacturing', Amer. Ceramic Soc. Bull., 78, 42-48, (1999)

8. Lynn N. Allen and Robert E. Keim: "An ion figuring system for large optic fabrication" pp. 348-363;

Lynn N. Allen and Henry W. Romig: "Demonstration of an ion figuring process" pp. 364-373; SPIE VMS40,

Selected Papers on Computer-Controlled optical Surfacing, ed. B. J. Thompson (1991)

9. Drueding, T.W., Fawcett, S.C., Wilson, S.R., Bifano, T.G., 'Ion Beam Figuring of Small Optical Components', Optical Engineering, 34, 3565-3571, (1995)

10. Leenaars, A.F.M., Huethorst, J.A.M. and van Oekel, J.J., 'Marangoni Drying: A New Extremely Clean Drying Process', Langmuir, 6, 1701-1703, 1990

11. Marra, J. and Huethorst, J.A.M., 'Physical Principles of Marangoni Drying', Langmuir, 7, 2748-2755, 1991

12. Wolke, K, Eitel, B., Schenkl, M., Rummelin, S., and Schild, R., 'Marangoni wafer Drying Avoids Disadvantages' Solid State Technology, 39, 87-90, 1996

13. Britten, J.A., 'Moving-Zone Marangoni Drying of Wet Objects Using Naturally Evaporated Solvent Vapor', U.S. Patent $5,660,642(1997)$

14. Britten, J.A., 'A Moving-Zone Marangoni Drying Process for Critical Cleaning and Wet Processing', Solid State Technology, 40, 143-148, (1997)

15. Scriven, L.E. C.V. Sternling, C.V., 'The Marangoni Effects', Nature 187 186-188, 1960

16. Schwider, J., Falkenstorfer, O., Schreiber, H., Zoller, A., Streibl, N., 'New Compensating 4-Phase Algorithm for Phase Shift Interferometry’, equation (6) Optical Engineering, 32, 183-1885, (1993)

17. B.C. Stuart, M.D. Perry, M.D. Feit, L.B. Da Silva, A.M. Rubenchik, J. Neev, "Machining of biological materials, dielectrics, and metals with femtosecond lasers", OSA Trends in Optics and Photonics Vol. 9, Lasers and Optics for Manufacturing, Andrew C. Tam, ed. (Optical Society of America, Washington D.C. 1997), pp. 94-98.

18. Bett, T.H., Barnes, A.R., Hopps, N.W., Jinks, P.M.R., Norman, M.J., '41 Application of Static Phase Control Elements to High Power Solid State Lasers’, SPIE Photonics West, Paper 4270, San Jose, CA, January 25, (2001)

19. Battersby, C.L., Sheehan, L.M., Kozlowski, M.R., 'Effects of Wet-Etch Processing on Laser-Induced Damage of Fused Silica Surfaces', Proc. SPIE, V3578, 446-455, (1998)

20. Hyde, R.A., "Eyeglass 1: Very Large Aperture Telescopes," Appl. Opt 38 4198-4212 (1999)

21. Barton, I.M., Britten, J.A., Dixit, S.N., Summers, L.J., Thomas, I.M, Rushford, M.C., Lu, K., Hyde, R.A., Perry, M.D., 'Fabrication of Large-Aperture Lightweight Diffractive Lenses for Use in Space', Applied Optics, 40, 447-451 (2001)

22. Dixit, S.N., Feit, M. D., Perry, M.D. and Powell, H.T., "Designing fully continuous phase screens for tailoring focalplane irradiance profiles", Opt. Lett. (21),1715-1717 (1996) 
23. Gordon, J., 'Navigating the Road Map progress on materials helps advance 157-nm mask substrate efforts, but pellicles remain a major challenge', OEMagazine, 24-25 (March, 2001)

24. Kohno, T., Matsumoto, D., Yazawa, T., Uda, Y., 'Radial shearing interferometer for in-process measurement of diamond turning` Optical Engineering, 39(10), 2696-2699, (2000) 